\title{
Sexual and reproductive rights of women with HIV in Costa Rica
}

\begin{abstract}
Summary
Since 1983 in Costa Rica, the first cases of HIV (human immunodeficiency virus) have occurred, and nowadays, the incidence of HIV infection has increased in recent years, making great progress with antiretroviral treatment (ART). But coexistence with HIV proves to be a stigma for society, which has generated a rejection on the part of Costa Rican culture. For this reason, the present article presents a qualitative study about the reality of the Sexual and Reproductive Rights of Women with HIV. A bibliographic review of 67 articles was carried out, including databases from Cochrane, EBSCO Host, MEDLine, bibliographic sources for database of hospital libraries and statistics up to 2015 on HIV incidence in Costa Rica. The main objective is to know the current situation of women's vulnerability to HIV discrimination, as well as their Sexual and Reproductive Rights. In the same way, in this small bibliographic study, the lack of information on the part of the citizenship in the subject of HIV, in prevention and protection of the Rights of people with HIV, is evidenced.
\end{abstract}

Volume 2 Issue I - 2017

\author{
Roison Ali Espinoza Reyes \\ Fisioterapeuta Especialista en Discapacidad y Políticas Públicas, \\ Spain
}

Correspondence: Roison Ali Espinoza Reyes, Fisioterapeuta. Especialista en Discapacidad y Políticas Públicas. Egresado de la Maestría de Derechos Humanos de la UNED. Servicio de Rehabilitación del Hospital, Spain, Email roison_ali@hotmail.com

Received: July 15, 2017 | Published: October II, 2017

Keywords: HIV, AIDS, sexual rights, reproductive rights, ART, pregnancy

\section{Introduction}

The National Report on Progress in the Fight against AIDS in 2012 shows that there are administrative and legal obstacles that prevent access to comprehensive care. There is disproportion to the political support of high officials of state institutions and between public institutions. Political support still lacks the full commitment of high authorities and is considered to be strengthened. Among other reasons, stigmatizing and discriminatory attitudes are also presented. The complementary support services they require (eg employment, accompaniment to their families) are very incipient. ${ }^{1}$

\section{Sexual and reproductive rights}

Sexual and reproductive rights (RSD) include the right to decide autonomously how to live sexuality and self-reproduction, and the right to access all health services that are required to execute these decisions in a safe and timely manner. They find their basis in human rights as the right to life, integrity, health, autonomy, dignity, information, equality and freedom from discrimination. The right to reproductive information obliges States to refrain from censuring, administratively or judicially, reproductive information that is in accordance with current legislation on the subject, such as the effects and effectiveness of planning methods family. In relation to women, RSDs involve the right to be treated as dignified and integral people and not as exclusively reproductive beings, and to exercise sexuality in a pleasant way without necessarily leading to pregnancy. The general objective is to integrate the universality of Sexual and Reproductive Rights, in this way to ensure the integral attention of the young population, women, indigenous communities among others, in this same way to contemplate the fulfilment of 3 of the objectives for the Development. ${ }^{2}$ Human immunodeficiency virus. (HIV) infection is considered a chronic disease since the 1990s, which is associated with a wide range of neurological, neuromuscular and cardiopulmonary conditions-deficiencies, therefore, disability. ${ }^{3}$ By increasing survival-survival, associated disability increases. ${ }^{3-5}$ Asymptomatic and symptomatic people with HIV experience higher levels of disability-physical disability compared to the general population. ${ }^{4}$ The main predictors of expectancy in people with HIV are: CD4 count, late HIV diagnosis, late ART initiation or incomplete adherence, stage of disease in which ART begins, whether or not to be maintained within the care system Health. Lifestyle and behavior are also important: smoking, alcohol consumption, intravenous drug use, coinfection with hepatitis, sexually transmitted infections (STIs). And finally, socio-demographic factors: gender, age, comorbidities associated with aging, ethnicity or country of origin, place of residence-neighbourhoods, socioeconomic status. The National Report on Progress in the Fight against AIDS in 2012 shows that there are administrative and legal obstacles that prevent access to comprehensive care. ${ }^{5}$ There is disproportion to the political support of high officials of state institutions and between public institutions. Political support still lacks the full commitment of high authorities and is considered to be strengthened. Among other reasons, stigmatizing an discriminatory attitudes are also presented. The complementary support services they require (eg employment, accompaniment to their families) are very incipient. Stigma According to the estimates of the Bulletin on HIV-AIDS in Argentina (Year XIII - November 2010, Number 27), the estimated number of people with HIV in our country amounts to 130,000 . The source also notes that "half of them know their condition and, of these, $69 \%$ is served by the public health system. During 2009, the Directorate of Aids and STDs of the Ministry of Health of the Nation (DSyETS) provided treatments for 29,886 of these people. The rest of the people with HIV receive it through Social Security and prepaid health services. The remaining $50 \%$ of people living with HIV would not know their serology, a consistent estimate with population surveys conducted in recent years. ${ }^{1}$

Stigma is recognized as one of the main obstacles to addressing prevention and care issues and ensuring access to essential health services for people living with HIV. Conducting a qualitative and quantitative investigation that describes and deepens the different types of stigma and allows a comparison at different geographical scales is a step forward so that the mentioned obstacles cease to be; also a great contribution to addressing the disease from the social vulnerability 
(Bloch 2010), one of whose manifestations is discrimination, and not just individual risk (6). Stigma and discrimination related to HIV/ AIDS occur in all countries and regions of the world and are triggered by many reasons, including:

1. Lack of awareness and lack of education about HIV/AIDS.

2. Myths about the ways of transmitting HIV and human sexuality.

3. Lack of comprehensive care, ARV treatment and a cure for AIDS

4. Distorted information from the media about the epidemic.

5. The taboos around sexuality. ${ }^{7}$

Methodological Framework To obtain results on the current situation of women with HIV in Costa Rica, a bibliographical review of 67 articles was carried out, aiming to know the global theme and the objectives for development, of the United Nations program, Adding to this the current situation of women in Latin America with HIV. This served as a tool to guide the needs that are required for the protection of the Rights of people with HIV. In this way, not only did the health condition become visible as a factor of vulnerability to discrimination, but other factors were presented such as the gender issue in the TRANS population and sexual diversity that identifies susceptibility by sexual orientation, And this is usually one of the greatest challenges in the subject of Human Rights. It also shows the current situation of national statistics up to 2015 of HIV cases and the incidence, laws and jurisprudence and national and international bodies that contribute to the improvement of quality of people living with HIV. Development In 2010, the new National Strategic Plan 2011-2015 was prepared, containing the priority actions and strategies that the country seeks to promote the comprehensive approach to the epidemic. However, it is striking that treatment; care and support are not mentioned in rehabilitation services. In Costa Rica, it is considered that opportunities should continue to be created to improve the quality of life of people living with HIV and/or AIDS and their Relatives. ${ }^{1}$ The General Law on HIV/AIDS since 1998, as well as its reform in 2008, aims to strengthen comprehensive health care services for people with HIV. ${ }^{8}$

\section{Vulnerability of women to HIV}

There are different vulnerabilities for men and women, many of which are the result of the process by which society dictates different behavior patterns each gender, as will be seen later. To be able to identify some of the determinants of these vulnerabilities associated to the fact of belonging to the female sex and the gender. The vulnerability of women has multiple faces: biological, epidemiological, social and cultural. ${ }^{9}$ In the case of biological vulnerability it has been found that in heterosexual relationships women is 2 to 4 times more vulnerable to HIV infection than men, because the area of exposure to the virus during sexual intercourse is the largest area In women, because viral load is higher in semen than in vaginal fluids, and because sexually transmitted infections (STIs) (co-factors of HIV infection) are more often asymptomatic and untreated in women than in women. In man which weakens the vaginal mucosa allowing entry of the virus, especially in adolescents, which is still immature genital tract (9). Gender vulnerability is strengthened when, in addition, other inequalities such as poverty or discrimination on the basis of ethnic or sexual preference are added, ie i.e. HIV/AIDS affects women as it affects them all equally (9). With regard to social vulnerability, women in the Third World continue to have less access to education and wage labor, making them more dependent on men and with limited access to adequate health information and services. It is important to note that the central issue here is that "the two genders are treated unequally in political, cultural and socio-economic terms, which can be seen both in couples and families, as well as in national or supranational societies or cultures". 9 According to epidemiological data cases of HIV/AIDS in control at the CCSS HIV clinics until December 31, 2015 .

\section{i) Active Patients:7214}

ii) Men:5873

iii) Women:1272 Patients with active treatment:5558

iv) Men:4553

v) Women:1005 New cases from January 1, 2015 through December 31, 2015:758

Restarting (number of patients who had abandoned follow-up at the clinic and restarted control in the reporting period): 157 . Deceased in 2015:110 Frequent in relation to HIV:91Felcome with less than 12months of being diagnosed:28 Pregnant:41 HIV positive mothers: $29 .{ }^{10}$

Among the main results we find mainly the vulnerability of women to HIV is because of their gender, here is an important fact and is that not only in Costa Rica is essential to take female empowerment, is that women in condition of Vulnerability to social risk due to their lack of education and growth lack standards of quality of life among them we have the lack of access to health and reproduction. These include the faster route of transmission by biological theory, and therefore much more susceptible to HIV, but also the geographical access to those places that lack comprehensive health care services. It is worth mentioning that access to education is reflected in part of the Reproductive Rights and it is here that responsibilities without socioeconomic positions are unconsciously presented. The system of the society in which we live has allowed the cultural practice of discrimination and stigma for lack of information, and is that currently a great influence is experienced by the media without scientific content and much less validity that have led to detachment by the advance Cultural society. Costa Rica has a large number of diversities, and it is something that has failed to universally address so many gaps of gender inequality is only some of those responsible. In this way we take responsibility for the issue for a common good, based on the highest ethical principles to maintain the quality of life of people with HIV. In addition, treatment has overcome the stigma associated with its diagnosis. ${ }^{9}$

\section{Conclusion}

With the advent of antiretroviral treatment in 1990, a better quality of life for people with HIV was achieved, more than 20 years ago, and goals have been sought to integrate and implement eradication for discrimination, Stigmas and cultural practices that society has been creating on the subject of HIV. It is precisely the lack of information on issues of Sexual and Reproductive Rights that we are constantly facing, and despite the knowledge we have about this subject, a valuable fact is that HIV is a chronic disease and that over more of two decades has sought to prevent the exclusion of this population, also the most important fact is that despite this condition will always prevail the sexual and reproductive rights of the population, especially the productive of women in Their health condition can be integrated into the right of family formation, be mothers and have excellent health. However, the challenges and goals are mediated by issues of 
gender equity, as well as female empowerment and socio-economic inequality gaps.

\section{Acknowledgements}

None

\section{Conflict of interest}

The author declares no conflict of interest.

\section{References}

1. CONASIDA. National report on progress in the fight against AIDS 20102011. San José Costa Rica; 2012.

2. Legislative assembly of the republic of costa rica. General health law No. 5395. San José, Costa Rica.

3. Odell M. Rehabilitation Medicine consultation in persons hospitalized wiht AIDS: an analysis of thirty cases. Am J Phys Med Rehabil. 1993;72(2):90-96.
4. Worthington $\mathrm{C}$, Myers T, Brien KO, et al. Rehabilitation professionals and human immunodeficiency virus care: results of a national Canadian survey. Arch Phys Med Rehabil. 2008;89(1):105-113.

5. Levinson SF, O Connell PG. Rehabilitation dimensions of AIDS a review. Arh Phys Med Rehabil. 199;72(9):690-696.

6. Petracci M, Romeo M, Stigma Index in people living with HIV Argentina. Fundación Huésped, Buenos Aires Argentina; 2011.

7. UNAIDS. Stigma and discrimination in HIV/AIDS in Ecuador Ecuadorian coalition of people living with HIV/AIDS. Ecuador; 2011.

8. Legislative Assembly, General Law on HIV/AIDS, retrieved from June 15 2015. India: Gazette publication; 1998.

9. Herrera C, Campero L. The vulnerability of women to HIV/AIDS: constant changes in the subject. Public Health Mexico. 2002;44(6):1-11.

10. Solano A. Statistical data of the HIV clinics of the Costa Rican social security fund. San José Costa Rica; 2016. 